International Journal of Advanced Academic Research (Social and Management Sciences) | ISSN: 2488-9849 Vol. 6, Issue 10 (October, 2020) | www.ijaar.org

Journal DOI: 10.46654/ij.24889849

Article DOI: 10.46654/ij.24889849.s61019

\title{
TOURISM ENTREPRENEURIAL OBJECTIVES, COVID-19 AND SUSTAINABLE TOURISM MARKETING STRATEGY
}

\author{
*Ekeke, J.N. ${ }^{1}$ and Sonari-Otobo, V.F. ${ }^{2}$ \\ ${ }^{1 \& 2}$ Department of Hospitality Management \& Tourism, Faculty of Management \\ Sciences,University of Port Harcourt, Choba, Rivers State, Nigeria. \\ *Author for correspondence, Mobile: +234-703-625-2485, Email: john.ekeke@ uniport.edu.ng
}

\begin{abstract}
The achievement of entrepreneurial objectives by tourism entrepreneurs is dependent on the existence of a dynamic, attractive, safe and competitive tourism destination capable of creating and delivering memorable experiential value which enhances tourist satisfaction and subsequent behaviouralintentions. However, the menace occasioned by the COVID-19 pandemic has posed a critical challenge and a bitter contradiction with the expectations and plans of tourism entrepreneurs all over the world. This explains why several attraction sites and other tourism and hospitality service organisations are either shut or operating at dismal operational levels with the consequent loss of jobs, leisure time as well as filing for bankruptcy claims, etc. The situation calls for a paradigm shift in destination marketing strategy. This present study seeks to situate the quest to achieve tourism entrepreneurial objectives during this austere and uncertain period (POST COVID-19) on the ability of tourism service providers to craft, implant and implement sustainable tourism marketing strategies. The study proposes academic, stakeholder and marketing implications.
\end{abstract}

KEYWORDS: Entrepreneurial objectives. Sustainable tourism marketing strategy. Tourism marketing environment.COVID-19. 


\section{Introduction}

Tourism as a global phenomenon is one of the largest industries that generate both positive and negative consequences. It has engendered economic prosperity, social, political and technological development. It has also enhanced "cultural understanding by creating awareness, respecting diversity of cultures and ways of life" (UNCSD 1999, p.1). As noted by Chebli, and Said, (2020, p.196), "tourism is regarded as a substantial industry, accounting for 10 per cent of world GDP, 7 per cent of international trade and 30 per cent of service operations". On the other hand, tourism activities in certain destinations have led to great negative impacts upon peoples' culture, environment and undermining the socio-economic wellbeing of the host community.

In another perspective, tourism is susceptible to various kinds of shocks; as tourism service suppliers live with and are continuously exposed to structural risks that are inherent to tourism such as value of currency fluctuations, seasonality of tourism demand, changing weather conditions as well as pandemics and epidemics such as SARS (2003), MERS, Ebola, and the most current COVID-19(Keller, 2020).

Previous crisis situations had serious negative effect on global tourism in terms of decrease in international flows and consequent decrease in tourist spending. For example, the SARS pandemic in 2003 led to decline of $-0.3 \%$ in international flows(UNWTO, 2020), while the economic recession of 2009 had a decrease of $4 \%$ in terms of flows and $5.4 \%$ in terms of tourist expenditure. However, for the impact of COVID-19, there is a forecast of 20-30\% for decrease in both tourist inflow and tourist expenditure, which implies a return to 2009/2010 level of international flows(Machiavelli, 2020, p.35).

The effect of COVID-19 on businesses, economy across the globe and the resulting marketing responses have been studied in various contexts, such as tourism and internet marketing (Babaev 2020; Sigala, 2020; OECD, 2020); tourist consumption behaviour (Chebli \& Said, 2020; Hong Cai, Mo, Gao, Xu, Jiang \& Jiang, 2020; Kim \& Lee, 2020); Igbo owned businesses in Nigeria (Chinedu, Dennis \& Chukwuemeka-Onuzulike, 2020). These studies tend to concentrate on the impact of COVID-19 on businesses across the various sectors of the economy and in specific terms the prediction of tourism demand, without identifying marketing responses aimed athelping entrepreneurs to achieve their objectives. The current stream of research tend to, "potentially offer limited scope to advance our knowledge on crisis management as well as to potentiate the pandemic's affordance to reset our research agendas and expand the contribution and frontiers of tourism research and industry" (Sigala, 2020, p.319).

To contribute to the closing of the identified apparent gap, this current study attempts to situate the achievement of tourism entrepreneurial objectives during this period on the ability of tourism stakeholders to adopt a sustainable tourism marketing strategy. Put differently,the main objective of the study is to examine how sustainable tourism marketing strategy could help in the achievement of entrepreneurial tourism objectives as a result of the effects of COVID-19 pandemic.

\section{Theoretical Foundations}

Entrepreneurs and scholars are aware that businesses do not operate in a vacuum. Rather they operate in the general business environment which is extremely dynamic in nature because it 
is fluid and ever changing. The implication isthat the future of every business is also susceptible to change. It is therefore the responsibility of business managers to keep a close watch at its internal and external environment via SWOT Analysis. A SWOT analysis is a structured technique used in evaluating the strategic position of a business or organisation by identifying its strengths, weaknesses, opportunities and threats. SWOT analysis helps entrepreneurs/managers to create a quick overview of an organisation's strategic position in the marketplace.

SWOT Analysis is based on the assumption that an effective strategy derives a sound "fit" between a firm's internal resources (strengths and weaknesses) and its external situation (opportunities and threats). This implies that, a good fit will seek to maximize a firm's strengths and opportunities and minimize itsweaknesses and threats. When properly applied, the technique is capable of assisting entrepreneurs/marketing managers to design and execute successful strategies in the marketplace. The first and principal focus in SWOT analysis is the information needed to identify opportunities and threats in the firm's external environment which is obtained from environmental and industry analysis (Pearce 11 \& Robinson 2011; Agbonifoh Ogwo, Nnolim \& Nkemnebe, 2007) and referred to as environmental scanning.

Environmental scanning is defined Byars (as cited in Nicolau, 2009, p.204), as "the systematic methods used by a company to monitor and forecast those forces that are external to and not under the direct control of the organization". The quest to analyse the environment is to detect changes that are capable of affecting the organisation. For example, environmental scanning could detect new facts or changes on consumer's tastes and preferences which is essentially good for the developmentof a company. This suggests that constant scanning of the environment through surveillance concerning relevant events is very important in developing competitive strategies to enable the firm compete in an efficient way in a business environment that is dynamic. The basic purpose of environmental scanning is to help management determine the future direction of the organization.

Strategically therefore, SWOT Analysis is a deliberate study of the general business environment of a firm with a view to finding a strategic fit between the organizational resources and the environmental opportunities and constraints. This implies that an organisation should carry out a situation analysis with a view to developing appropriate strategies with which to serve their target market(s) satisfactorily. Such situation analysis helps a firm to identify and select the more favourable opportunities they can capitalise on, and provide value to the customers.

In tourism marketing, the analysis of the environment is one of the most critical functions to be performed because of the fact that the definition of any kind of strategy to be implemented by any firm has to be guided by an accurate scanning of the relevant factors that may, in a way, condition or affect decision-making. Success will be achieved easily if firms are ableto match the threats and opportunities in the environment with appropriatestrategies. For example, the constant scanning of the business environment is capable of revealing changesin tourists' preferences. This will certainly trigger a response by the tourism firms in the destination by adjusting their marketing strategies accordingly. 


\section{Tourism Entrepreneurial Objectives}

Operationally, entrepreneurship could be defined as the process whereby people acting individually or as a group create a new firm which produces goods and/or services of value (Acs, 2006). As a process, it involves risking resources by entrepreneurs, based on an idea that is linked to a business opportunity to develop goods and/or services that a target market will perceive as valuable and willing to pay money in exchange for what is produced. The enterprise involved is expected to get value in return (Kuenyehia, 2012). Entrepreneurial objectives include the quest to create new businesses; generate ideas; to convert the idea into valuable products and to get value in return, when the products are delivered to the target market.

In the tourism industry, entrepreneurs drive the tourism supply chain. To achieve progress in this regard, collaboration is rife in the industry. In one perspective, tourism service providers could collaborate to enhance operational efficiency, while they could collaborate with the public sector in a Public Private Partnership (PPP) arrangements in another perspective.

\section{COVID-19 pandemic}

COVID-19 is an acronym for the ongoing ravaging pandemic-coronavirus which is said to have originated from Wuhan, China in 2019. The impact of COVID-19," affects every area of our lives, and especially how we spend our money" (Babaev, 2020, p.280). To date, more than $4 \mathrm{~m}$ people in 180 countries are reported to have been infected and sadly, above 300 thousand dead.

The impact of COVID-19 on the global economy is extremely detrimental as exemplified by job lossesand business closures. As noted by Bloom Consulting (2020) in comparable terms, the economic recession in 2008, 22m jobs were lost, while in the second quarter of 2020 during the ravenous COVID-19, more than 195 million jobs were lost around the world with many companies like airlines seeking bailout opportunities to survive Post COVID-19 era. Empirical evidence reveal that the pandemic has "led to a supply shock that proved that tourism related businesses and industries are less resilient or robust to master bad times than their lobbyist always pretend"(Keller 2020, p.16)

\section{Sustainable Tourism Marketing Strategy}

Kotler and Armstrong (2010 p.608) defined sustainable marketing as the type of "marketing that meets the present needs of consumers and businesses while also preserving or enhancing the ability of future generations to meet their own needs". This implies that sustainable marketing concept considers both the future wellbeing of consumers (societal marketing concept) and the future company needs (strategic planning concept). Fuller (1999, p.4) defined sustainable marketing as, "the process of planning, implementing, and controlling the development, pricing, promotion and distribution of products in a manner that satisfies the following three criteria: (1) customer needs are met, (2) organizational goals are attained, and (3) the process is compatible with ecosystems". This definition was based on the author's sustainable marketing management framework which was designed to promote production and consumption practices that preserve environmental integrity.

Sustainable tourism marketing could therefore be defined as the process of meeting the present needs of tourists, tourism service providers and the host communities while also preserving or enhancing the ability of future generations to meet their touristic needs. To 
achieve this purpose, tourism marketers are expected to develop a sustainable marketing strategy which acts as a mechanism for value delivery. As noted by Ramaswamy and Namakilinia (2009), it is marketing strategy that helps organisations to achieve competitive advantage in the marketplace. However, marketing strategy is not a standalone exercise. It is very critical and an integral part of marketing planning.

A simple pattern of developing marketing strategy involves value selection (STP+ Branding) and value delivery (Marketing mix elements). Value selection represents segmentation, targeting, positioning and branding, while the value delivery represents the tactical marketing aspect of the strategy. An application of this model to developing of sustainable tourism marketing strategy could be described as follows:

\section{Marketing Strategy (Value Selection)}

Segmentation: The quest for sustainability tourism calls for greater considerations for market segmentation. This is with a view to concentrating on the market segment of visitors that are economically attractive and being susceptible to messages aimed at encouraging them to adopt sustainable behaviours.

Target Marketing: A destination needs to make choice of the market segment to serve. This is done through evaluating the market segments to determine the attractiveness of each segment and the capability of the destination to compete in the market segment. As noted above, the market(s) selected should be economically attractive and has the willingness to adopt sustainable behaviours. The destination and the tourism service providers should be able to meet the needs of the chosen market.

Positioning: To develop an effective marketing strategy for a sustainable destination, the next step to take is to position the destination very clearly in the marketplace by creating and maintaining a distinctive place in the marketplace for the destination and its sustainable products. The essence of positioning is to create a differential advantage in the marketplace by using the tourism sustainable marketing mix elements.

\section{Sustainable marketing strategy (Tactical marketing)}

Product: Destination aspiring to enhance tourism sustainability are expected to promote sustainable tourism products. Examples include;

- Providing conservation holidays

- Vacation packages using public transport rather than private cars

Destination marketing organisations are to avoid offering products that are not sustainable

- Hunting tips. This will prevent wild life extinction

- Preventing holidays where tourists consume local resources that are in short supply such as water. This will cause problem for the rural dwellers.

Packaging: The tourism product is a composite product because it consists of a complex set of tangible goods and services (attractions, travel trade services, food and beverage, accommodation, transportation services, etc.). Packaging as a tourism marketing mix element refers to combining two or more of the product-service mix of the tourism experience and 
sold as one product. This explains why we have tour operators who sale packaged tours to interested tourists.

Programming: Programming connotes better ways of packaging tourism events, special activities and other programmes at destinations for the delight of the target market. The primary objectives of programming are to add value to the destination appeal and increase visitors' spending. In an eco-tourism destination the DMO could develop information and education programmes in co-operation with local stakeholders to enhance appropriate behaviour.

Price: Due to its exclusive nature, the customer perceived value in sustainable destination should be very high. The implication is that tourism service providers should ensure satisfactory experience with comparable experiential value for the tourists. The price should be such that will cover the cost of service and allow the organizations to make sufficient profit in order to remain in business. From the profits made, the service providers should be able to ensure an appropriate level of benefits for the host community.

Place: Place refers to the destination where the tourism service is been experienced as well as the channels of information used in linking the target market with the service providers in the destination. As noted by Dinan (2000), if the DMO and the stakeholders decide to provide a tourism code of conduct for potential visitors to a destination, they will seek the co-operation and commitment of travel intermediaries (travel agents and tour operators) and managers of attractions. This approach is to enhance sustainable education for the tourists while stillat the tourism generating region.

In maintaining sustainability, Swarbrooke (1999) suggested two areas that could assist in this regard;

- Encouragement of direct selling to potential tourist with a view to achieving better prices for the consumers, and

- Monitoring travel intermediaries to ensure the sale of tourism products is done ethically and does not in any way cause unrealistic expectation in the minds of the tourists.

Promotion and Education:The promotion of a destination may involve the following communication tools; advertising, e-advertising, public relations, publicity, social media advertising. Whatever means used should promote the destination concerned as eco-friendly and emphasize the need for responsible tourism and sustainability.

Process:Process as a sustainable marketing mix element describes the 'how' of service delivery to the target audience. Put differently, the process describes how the entire service delivery system operates, that is, the policies and procedures adopted as a guide to enhance and sustain quality service delivery at an eco-friendly destination. Tourists/visitors are usually educated with a view to modelling behaviour of tourists/visitors to conform to sustainability.

Physical Evidence: The components of physical evidence include all the physical elements and materials which are directly or indirectly associated with the eco-friendly destination. Typical examples include; the environment (structures and compound layout), furnishings, colour, atmosphere, noise level, facilitating goods etc. The component of physical evidence could be classified into two: essential evidence (what tourists come in contact with at the 
destination) and peripheral evidence (usually possessed as part of the purchased service but has little or no independent value such as airline tickets and admission tickets).

Partnership: The delivery of service that will enhance the sustainability of a destination demands partnership initiatives among tourism service providers operating in that destination. The DMO is expected to coordinate all the stakeholders in the destination with a view to achieving tourism sustainability. For example, the DMO may partner with transport companies to use cars with minimal gas emission, reduce tourism-related traffic, etc. DMO may also partner with the host community, NGOs, National Tourism Organizations (NTOs) to create and promote environmentally friendly destination.

People: The categories of people expected in a tourism destination are; tourists, host community and service employees. The tourists are expected to abide by the rules governing tourist behaviour in the destination. For example, the tourists are expected to respect the cultural heritage of the host community. The quest to ensure that the host community derive economic benefits from tourism activities could lead to the tourism service providers providing job opportunities for the local people. The friendliness of the local people with the visitors will enhance understanding and corporation.

\section{Tourism Entrepreneurial Objectives, COVID-19 and Sustainable marketing mix elements}

The enterprises created by entrepreneurs which act as vehicles used in achieving their objectives including tourism and hospitality firms, operate within the context of a business environment that is characterised by uncertainty and capable of enhancing the achievement of entrepreneurial objectives or act as a threat. COVID-19 has proven the vulnerability of tourism businesses to environmental shocks, to the extent that tourism and hospitality firms suffered greatly in the process (Keller, 2020; Bloom Consulting, 2020), with some seeking for bailouts to survive the effect of the pandemic. Sigala, (2020) found that various stakeholders notably, the government and destinations offered several stimulus packages and interventions such as; tax reliefs, subsidies, deferrals of payments, with a view to ensuring the viability and continuity of tourism firms and jobs.

In Nigeria, Chinedu, et al. (2020) investigated the impact of covid-19 on the survival of Igbo owned businesses in Nigeria. The empirical study found that the restriction of movement affected business sustainability as $96 \%$ change in the sustainability of Igbo owned businesses was explained by changes in restriction of movement during the pandemic in Nigeria.

Nazneen, Hong, and Ud Din (2020) investigated the effect of COVID-19 on tourists' travel risk perceptions in China. The population of study were both Chinese and foreigners from thirty-two different countries of the world that had different geographical and cultural background. The study findings indicate that the pandemic affected the attitude of the respondents towards travel. Tourists' perception of risk had a significant negative effect on their travel decision, with significant number affirming that the pandemic created anxiety and reduced their travel plans for the next 12 months including their perceptions of hygiene and safety. Some also indicated that if they decide to travel it will be with family members rather than travelling groups and most likely to reduce the length of their stay at their preferred destinations. This specifies that tourists are sensitive to crises events. 
Tourism and hospitality firms (airlines, bars, hotels, restaurants, airports, etc.,) were all closed for business by different national authorities. This scenario is understandable because, as argued by Najar (2018, p.22), "when tourism ceases to be pleasurable due to actual or perceived risks, tourists exercise their freedom and power to avoid risky situations or destinations". In the case of COVID-19,Bloom Consulting (2020, p.9) noted that;

COVID-19 has completely devastated tourism. We have seen an estimated loss of up to 440 million International arrivals that has set us back 7 years. The Virus has put world tourism at a loss of up to 450 billion dollars.

From the foregoing, we postulate as follows;

\section{P1: The quest to achieve tourism entrepreneurial objectives across the globe has been adversely affected by COVID-19 pandemic.}

\section{P2: COVID-19 pandemic is a threat to tourism businesses across the world.}

From the study of the business environment, one of the objectives of environmental scanning is to identify changes in the tastes and preferences of consumers with a view to crafting an appropriate marketing response strategy that is capable of enabling the firm to still meet the needs and expectations of the target market profitably. Najar $(2018$, p.22) observed that "tourism is highly vulnerable to internal and external shocks as diverse as economic downturns, natural disasters, epidemic disease, and international, national conflicts". Such is the case with the current COVID-19 pandemic which has crippled several tourism and hospitality businesses which has impacted greatly on tourist behaviour.

Chebli and Said (2020) examined the effect of COVID-19 on tourist behaviour. The study found that the pandemic will lead to changes in tourist behavioural intentions in the demand and consumption of tourism and hospitality services. Such changes in behavioural intentions include personal safety, conviction and attitude and economic expenditure. For example, in the United States of America, Kim and Lee (2020) investigated the effects of the perceived threat of COVID-19 and the salience of the virus on diners' preference for private dining facilities in restaurants. The findings of the study showed that the salience of the virus generates a preference for the private (vs. non-private) dining table and for a preference of restaurant with private rooms.

From the foregoing, what is required is for tourism entrepreneurs/marketing managers to develop an appropriate marketing response towards COVID-19. It is on this basis that this study argues for the adapting of sustainable tourism marketing strategy as an appropriate marketing response to COVID-19 pandemic. Sustainable marketing strategy is deemed appropriate because, sustainable tourism is capable of striking a balance between the needs of different stakeholders (tourism service organisations, destination marketing organisations, public entities, host communities) and the tourists and visitors who travel to destinations (Cronin, 1990; Cater, 1993; Sharpley, 2000). This is because sustainable tourism marketing strategy is capable of mitigating overtourism and its dangers as well as promotion of responsible tourism and sustainable consumption.

The strategy is made of two parts: value selection and tactical marketing (value provision and communication) (Kotler, 2001). The value selection ensures that the market segmentation will identify tourism market segments available, while targeting will select the market 
segments that will be able to abide by the COVID-19 protocols and be capable of paying a premium price that may likely be charged in some destinations. To complete the process of choosing the value, positioningof the destination as being safe from COVID-19 infection is developed in a well crafted positioning strategy. The destination is expected to be branded to reflect its COVID-19 compliancestatus.

The tactical marketing component which defines the value-delivery sequence is expected to be positioned to deliver memorable tourism experiences using the sustainable tourism marketing mix elements. The destination tourism product which is composite in nature requires reasonable degree of innovativeness in the area of provision of virtual tourism experiences, visitor and staff protective equipment, etc. Pricing of destination which is diverse in nature should be determined bearing in mind that some tourists/visitors are sensitive to discretionary spending during this period. Discounts by hotels and restaurants could be attractive during the post COVID-19 era. Destination promotion should highlight the preventive measures taken by destinations, and by extension promote the newly developed destination capabilities with a view to rebuilding consumers' trust and confidence as well boosting tourists' spending(Bloom Consulting, 2020).

Promotion goes seamlessly with education of the target market on the need to comply with COVID-19 protocols. In terms of place, green accessibility is recommended where private vehicles will be preferred over commercial buses. Tourism service providers in a destination are expected to collaborate among themselves in the area of joint marketing planning to enhance COVID-19 tourism product development and marketing. In the same vein, tourism service providers are expected to partner/collaborate with health regulatory agencies, like the Nigerian Centre for Disease Control (NCDC) in the case of Nigeria, National Health Service (NHS) in United Kingdom, etc.

With regard to people, the service employees should be properly trained and motivated to deliver quality service and ensure memorable tourism experiences. The local people in the host community should be properly trained also, with a view to enhancing their safe interaction with the tourists. The process of getting access to services at destinations should offer safety measures while the physical evidence should reflect social distancing rules.

The foregoing suggests that;

P3: The formulation and implementation of sustainable tourism marketing strategy will certainly align with the needs and expectations of tourists, who are currently changing their touristic behaviour in line with the new normal.

P4: The implementation of sustainable tourism marketing strategy will allow tourism service organisations to open for business and thus help tourism entrepreneurs to achieve their set tourism entrepreneurial objectives.

\section{Conclusion and Discussion}

The current business climate across the world show that tourism businesses are affected drastically (Keller, 2020; Bloom Consulting, 2020), explaining why airlines, hotels, bars, transport companies, attraction sites, etc., are all battling for survival due to the ravaging impact of COVID-19 pandemic. Loannides, and Gyimóthy, (2020, p.624) noted that "the COVID-19 pandemic has halted mobility globally on an unprecedented scale, causing the neoliberal market mechanisms of global tourism to be severely disrupted". This condition 
tallies with the theory of SWOT Analysis wherein the environmental threats such as COVID19 posses great challenges towards the accomplishment of entrepreneurial objectives especially in the tourism industry.

Richards (2020) posited that pandemic induced crises such as SARS caused serious widespread disruption for global travel in 2009. The argument of Keller (2020, p.23) that, "tourism is not an autonomous sector and depends on the growth path of the world economy for which the OECD forecasts a strong worldwide recession due to the ravaging impact of COVID-19" shows that tourism is susceptible to the vagaries of the tourism marketing environment.

The quest to contain the COVID-19 pandemic emphasizes on social distancing which limits the proximity between people, exactly what tourism tends to favour, during the trip, during the stay and participating in touristic activities. The implication is that tourism "ends up being the sector most affected by the pandemic in all its productive activities"(Machiavelli, 2020, p.37). This makes a case for a paradigm shift in crafting of marketing strategy capable of enhancing productive activities at tourism destinations without breaking the COVID-19 protocols.

The foregoing reality, proposes that tourism entrepreneurs need to adapt sustainable tourism marketing strategy to enhance the economic viability of the tourism industry in the midst of COVID-19 fears. This is because, the sustainable tourism marketing strategy is capable of utilizing its value creation and tactical marketing components to attract reasonable number of tourists/visitors to a tourism destination and enhance sustainable consumption of tourism products. However, it should be emphasized that, a sustainable tourism marketing initiative may not promote maximum organizational profitability, but it has the capacity to bring back life to tourism businesses, support social distancing, enhance the socio-economic wellbeing of the local people and preserve a healthy environment.

\section{Implications for policy and management}

When tourists or visitors who are consumers of tourism services are aware of a tourism destination that is COVID-19 compliant, they are likely to visit such a destination hence contributing to a destination's profitability which by extension meets the objectives of tourism entrepreneurs. Therefore, in order to ensure tourists' destination brand loyalty, tourism entrepreneurs/managers ought to invest in strategies that foster tourism sustainability and tourist satisfaction. The current study is an attempt to situate the achievement of tourism entrepreneurial objectives during this COVID-19 pandemic on the adoption of tourism sustainable marketing strategy by tourism service providers at a global context. By and large, the findings of this conceptual study are expected to have provided fruitful implications to tourism practitioners, academicians and regulators.

On the practitioners' side, the important influence of crafting a COVID-19 compliant tourism sustainable marketing strategy is highlighted. This study therefore submits that tourism marketers can benefit from the implications of these findings. For instance, given the robust relationship between tourism sustainable marketing strategy on tourists' behavioural intentions, tourism marketers ought to pay attention to both value creation and the tactical marketing components of the tourism sustainable marketing strategy. For example, by improving the quality of destination brands through sustainable induced quality service, 
tourists are likely to be satisfied and trust such destination brands. Eventually, the tourism customers will become attached to such a destination brand that satisfies their needs and they perceive to be trustworthy in terms of safety from COVID-19 infection.

The foregoing suggest that today's tourism companies need a planning model that allows them to incorporate COVID-19 as they anticipate the future and to use this anticipation in conjunction with an analysis of the organisation'sinternal environment (mission, strengths and weaknesses) as well as external environment (opportunities and threats) with a view to defining strategic issues. This implication of the study will help tourism service providers to adapt to the new normal, by developing capabilities that will reduce drastically the likelihood and impacts of COVID-19 threats.

On the academic side, this study makes a significant contribution to the SWOT Analysis, tourism environment management and destination marketing literature by systematically exploring the role tourism sustainable marketing strategy could play in repositioning the tourism industry for survival during and post COVID-19 pandemic at a global scale. Overall, the current study findings provide tentative support to the proposition that adapting the tourism sustainable marketing strategy should be recognized as significant marketing response strategy during and post pandemic management initiative.

On the tourism regulators' side, this study makes a significant contribution to the effect that instead of legislating an outright closure of all tourism attractions sites and by extension tourism service providers, effort should be made to promote the adoption of sustainable tourism marketing strategies as the basis for opening tourism destinations for business. This will limit the demand for bailouts from various national governments by tourism organizations.

\section{Limitations and Future Research Directions}

This study is conceptual in nature. A qualitative study where interviewing of tourism entrepreneurs/mangers is carried out to determine their views on the quest to adapt sustainable tourism marketing strategies will help to highlight the relationship amongst tourism entrepreneurial objectives, COVID-19 and sustainable tourism marketing strategy. 


\section{References}

Acs, Z. (2006). How is entrepreneurship good for economic growth. Innovation. Winter: 97107.

Agbanifoh, B.A, Ogwo, E.O., Nnolim DA \&Nkemnebe A.D (2007) Marketing in Nigeria: Concept Principles and Decisions Aba: Afritowers Publishers Ltd.

Babaev, J.(2020) Influence Of The Covid-19 Pandemic Coronavirus Of The World Economy: In Case Of Tourism And Internet Marketing. International Journal of Scientific \& Engineering Research, 11, (7), 279-284.

Bloom Consulting(2020) COVID-19 The impact on tourist behaviours. Retrieved from http://www.bloom-consulting.com

Cater, E. (1993) Ecotourism in the Third Word. Tourism. Management. 14, 85-90.

Chebli, A, \& Said, F.B (2020). The impact of COVID-19 on tourist consumption behaviour : A perspective article. Journal of Tourism Research. 7(2), 196-207.

Chinedu, O. F., Dennis, M. O., \& Chikwuemeka-Onuzulike, N. (2020). Impact of Covid-19 on the survival of Igbo owned businesses in Nigeria: the nexus. International Journal of Financial, Accounting, and Management. 2(2), 121-130.

Cronin, L. (1990) A strategy for tourism and sustainable development. World Leisure Recreation. 32, 12-18.

Fuller, D.A. (1999) Sustainable Marketing - Managerial - Ecological Issues, Thousand Oaks: SAGE Publications.

Hall, C. M., Scott, D., \&Gössling, S. (2020). Pandemics, transformations and tourism: Be careful what you wish for. Tourism Geographies. https://doi.org/10.1080/14616688.2020.1759131.

Hong, Y., Cai, G., Mo, Z., Gao, W., Xu, L., Jiang, Y., \& Jiang, J.(2020) The Impact of COVID-19 on Tourist Satisfaction with B\&B in Zhejiang, China: An ImportancePerformance Analysis. International Journal of Environment Research and Public Health, 17, 3747, 1-19.

Ioannides, D \&Gyimóthy, S. (2020) The COVID-19 crisis as anopportunity for escaping the unsustainable global tourism path, Tourism Geographies, 22:3,624-632, DOI: 10.1080/14616688.2020.1763445.

Keller, P. (2020) Corona pandemic as exogenous shock for international tourism: a context analysis In Burini, $\mathrm{F}(\mathrm{Ed})$ Tourism facing a pandemic: from crisis to recovery(pp.1524) Bergamo: UniversitàdegliStudi di Bergamo

Kim, J \& Lee, J.C..(2020)Effects of COVID-19 on preferences for private dining facilities in restaurants Journal of Hospitality and Tourism Management 45, 67-70. 
Kotler, P. \& Armstrong, G. (2010), Principles of Marketing 13thed. New Delhi: Prentice-Hall, Inc

Kotler, P. (2001), Marketing Management the Millennium ed. New Delhi: Practice Hall of India.

Kuenyehia, E.N(2012). Kuenyehia on Entrepreneurship. Accra: Flipped Eye Publishing.

Macchiavelli, A., (2020) A fragmented system in the face of the crisis InBurini, F. (Ed)

Tourism facing a pandemic: from crisis to recovery(pp.33-44) Bergamo:

UniversitàdegliStudi di Bergamo

Najar, A.H. (2018) Recovery marketing activities (RMA's): A tool to manage destination in conflict situation- Research Literature Review. South Asian Journal of Tourism and Heritage. 11(1), 22-32.

Nazneen, S., Hong, X., \&Ud Din, N (2020) COVID-19 Crises and Tourist Travel Risk Perceptions (May 4, 2020). Available at SSRN: https://ssrn.com/abstract=3592321 or http://dx.doi.org/10.2139/ssrn.359232

Nicolau, J.L. (2009). "Scanning the tourism marketing environment”. Esic Market, 132, 203 222.

OECD (2020) Tourism policy responses to coronavirus (COVID-19) Available at: https://www.oecd.org.coronavirus

Pearce 11, J.A \& Robinson, R.B (2011) Strategic Management: Formulation, Implementation and Control. $12^{\text {th }}$ ed. New York: McGraw-Hill Education

Ramaswamy, V.S \&Namakumari, S (2009) Marketing Management $4^{\text {th }}$ ed. Delhi: Macmilan Publishers Indian Limited

Richards, G., (2020)The impact of crisis on travel: Covid-19 and other shocks In Burini, $\mathrm{F}(\mathrm{Ed})$ Tourism facing a pandemic:from crisis to recovery(pp.25-32) Bergamo: UniversitàdegliStudi di Bergamo

Sharpley, R. (2000)Tourism and sustainable development. Journal of.Sustainable Tourism 8, $1-19$.

Sigala, M, (2020) Tourism and COVID-19: Impacts and implications for advancing and resetting industry and research. Journal of Business Research 117 (2020) 312-321

Swarbrooke, J. (1999), Sustainable Tourism Management, Wallingford: CABI International

Tao,(2005), "Sustainable Tourism Development", Ohauo University.

UNCSD, (1999). Sustainable tourism: A non-governmental organisation perspective. New York: Department of Economic and Social Affairs Commission on Sustainable Development

UNWTO. (2020). Tourism and covid-19. Retrieved from https://www.unwto.org/tourismcovid-19 